\title{
Single hormone receptor-positive breast cancer patients experienced poor survival outcomes: a systematic review and meta-analysis
}

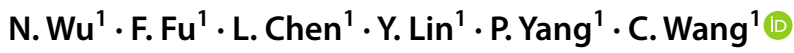

Received: 12 March 2019 / Accepted: 28 May 2019 / Published online: 20 June 2019

(c) The Author(s) 2019

\begin{abstract}
Background The prognostic and clinical significance of single hormone receptor expression in breast cancer has not been clearly established. The goal of this study was to conduct a meta-analysis to compare the clinical outcomes of patients with $\mathrm{ER}+\mathrm{PR}-$ tumours and $\mathrm{ER}-\mathrm{PR}+$ tumours to those of patients with $\mathrm{ER}+\mathrm{PR}+$ tumours.

Methods A systematic review of the literature was conducted to identify studies that compared the clinical outcome of patients with ER+PR- tumours or ER-PR+ tumours with those of patients with ER+PR+ tumours. A total of 18 studies met the inclusion criteria and included 217,485 women. Standard methods for meta-analysis were used, including fixedeffect models.

Results Patients with ER+PR - tumours or ER-PR+ tumours had significantly worse DFS (HR 1.60, 95\% CI 1.44-1.77 and HR 2.27, 95\% CI 1.67-3.09), BCSS (HR 1.43, 95\% CI 1.33-1.53 and HR 1.82, 95\% CI 1.68-1.98) and OS (HR 1.38, 95\% CI 1.28-1.47 and HR 1.48, 95\% CI 1.17-1.89) than those of patients with ER+PR+ tumours. In subgroup analyses, patients who had $\mathrm{ER}+\mathrm{PR}$ - tumours experienced a higher risk of recurrence than patients with ER+PR+ tumours in the HER2(HR 1.57, 95\% CI 1.32-1.87), LN - (HR 2.07, 95\% CI 1.44-2.86) and endocrine therapy (HR 1.65, 95\% CI 1.45-1.89) subgroup. Patients who had HER2 - and ER-PR+ tumours had an increased risk of recurrence compared with patients who had HER2- and ER+PR+ tumours (HR 3.10, 95\% CI 1.92-5.10).

Conclusions Among patients with hormone receptor-positive breast cancer, patients with either ER+PR - tumours or ER$\mathrm{PR}+$ tumours have a higher risk of recurrence and a shorter survival time than those with ER+PR+ tumours. Patients with both types of breast cancer need additional or better treatments.
\end{abstract}

Keywords Breast cancer $\cdot$ Hormone receptor positive $\cdot$ Estrogen receptor $\cdot$ Progesterone receptor $\cdot$ Disease-free survival . Overall survival $\cdot$ Breast cancer-specific survival

\section{Introduction}

N. Wu and F. Fu contributed equally to this work.

Electronic supplementary material The online version of this article (https://doi.org/10.1007/s12094-019-02149-0) contains supplementary material, which is available to authorized users.

\section{F. Fu}

412555736@qq.com

C. Wang

chuanwang1968@outlook.com

1 Department of General Surgery, Affiliated Union Hospital of Fujian Medical University, No. 29, Xin Quan Road, Gulou District, Fuzhou 350001, Fujian, China
Breast cancer (BC) has been known to be an endocrinerelated cancer since Beatson demonstrated that tumours regressed after oophorectomy in advanced breast cancer patients [1]. Jensen et al. then found that there are a large number of estrogen receptor (ER)-positive and progesterone receptor (PR)-positive tumours in breast cancer patients, and there was a possibility that these receptors contribute to the progression of BC. Currently, endocrine therapy plays an important role in the comprehensive treatment of breast cancer. The status of estrogen receptor (ER) and progesterone receptor (PR) expression is commonly used to direct the treatment strategies for $\mathrm{BC}$ patients because of their predictive value in prognosis and endocrine therapy (ET) responsiveness. 
It is commonly accepted that $\mathrm{ER}+$ and $\mathrm{PR}+\mathrm{BC}$ require ET. The ER status is now widely considered to be the most important predictive factor for determining the optimal therapeutics for BC patients and patients with ER+ tumours show a trend towards increased survival [2, 3]. However, routinely evaluating the PR status to guide treatment options and recognizing it as an independent predictive factor remain controversial $[4,5]$. Olivotto claimed that treatment decisions in ER+ patients will not be affected by the PR results [6]. However, studies have shown that the absence of PR expression has a powerful prognostic value in ER+ breast cancer patients, emphasizing the importance of re-evaluating PR status as a biological marker for poor prognosis [7]. The clinicopathological characteristics and prognosis of ER-PR+ tumours are not well known due to the small number of patients with this type of disease. The ER-PR+ group is reported to be only $1-5 \%$ of all breast cancer patients. Whether the ER-PR+ phenotype is a unique biological entity is still debatable and remains poorly understood. Patients with ER-PR+ tumours seem to fall short of the expectations for survival after systemic therapy, and tamoxifen does not reduce recurrence in patients with ERnegative tumours [8].

In this systematic review and meta-analysis, we evaluated the different clinical outcomes among the single hormone receptor-positive phenotypes (ER+PR- and ER-PR+ tumours) and the double hormone receptor-positive phenotype (ER+PR+ tumours), especially after ET. We included overall survival (OS), BC-specific survival (BCSS) and disease-free survival (DFS). Our aim was to identify which patients tend to benefit from ET and to determine whether any additional value was provided by the double-positive $\mathrm{ER}+\mathrm{PR}+$ phenotype in hormone receptor-positive BC. As a result, we will be able to perform better management of $\mathrm{BC}$ patients according to their different ER and PR expression patterns.

\section{Methods}

\section{Data sources and search strategy}

We identified potentially relevant studies by systematically searching Google Scholar and using the following combination of key words: ER+/PR- and breast cancer and survival; ER positive/PR negative and breast cancer and survival; ER-/PR+ and breast cancer and survival; and ER negative/PR positive and breast cancer and survival. The COCHRANE database search strategy used the terms "breast cancer", "estrogen receptor", "progesterone receptor", "positive", "negative", "endocrine therapy" and "prognosis". PUBMED was searched with the terms "breast neoplasms", "estrogen receptor", "progesterone receptor", "positive", "negative", "endocrine therapy", "endocrine therapy" and "prognosis". The last search was performed in January 2017.

\section{Study selection}

We included studies that compared the survival between $\mathrm{ER}+\mathrm{PR}+\mathrm{BC}$ and $\mathrm{ER}-\mathrm{PR}+\mathrm{BC}$ or $\mathrm{ER}+\mathrm{PR}-\mathrm{BC}$ patients. The following three inclusion criteria were applied to the studies that were retrieved: (1) all patients having hormone receptor-positive breast cancer (positive for estrogen receptor, progesterone receptor or both); (2) clear description of the status of the ER and PR; and (3) quantified DFS, OS or BCSS by effective measures such as hazard ratios (HRs) or relative risks (RRs). For articles based on the same population, only the least informative article was excluded, and the most recently published article was enrolled in the study. Articles not in English or Chinese were excluded (Fig. 1).

\section{Data extraction}

From each study, we extracted the name of the first author, date of publication, number of patients reported, years that the patients were recruited, follow-up time, hormone receptor status, status of the lymph nodes, location where the study was performed, the main treatment and hazard ratios (HRs) or relative risks (RRs), with the respective 95\% confidence intervals (95\% CIs).

\section{Statistical analysis}

The hazard ratios (HRs) with their corresponding 95\% CIs were used to assess the difference in survival between the single hormone receptor-positive phenotype and the double hormone receptor-positive phenotype, according to the methods described by Parmar et al. [9]. The RR was considered the HR. When the HR of an event in the control arm versus the experiment alarm was reported, we obtained the HR of the research arm versus the control arm by calculating the reciprocal of the HR, i.e. $1 / \mathrm{HR}$ and the associated CI [10]. An HR > 1 implied worse survival, favouring single hormone receptor-positive patients. A fixed-effect model was used for our main results.

The heterogeneity of the included studies was evaluated with the $I^{2}$ statistic $[11,12]$. The $I^{2}$ values $>50 \%$ indicated the presence of significant heterogeneity between studies. The subgroup analysis was based on ET, lymph node (LN)negative status and human epidermal growth factor receptor 2 (HER2)-negative status. We used funnel plot analyses and the trim and fill method to investigate the publication bias $[13,14]$. A quality assessment was performed for each of the acceptable studies using the Newcastle-Ottawa scale [15]. 
Fig. 1 Selection of included studies. ER estrogen receptor, $P R$ progesterone receptor

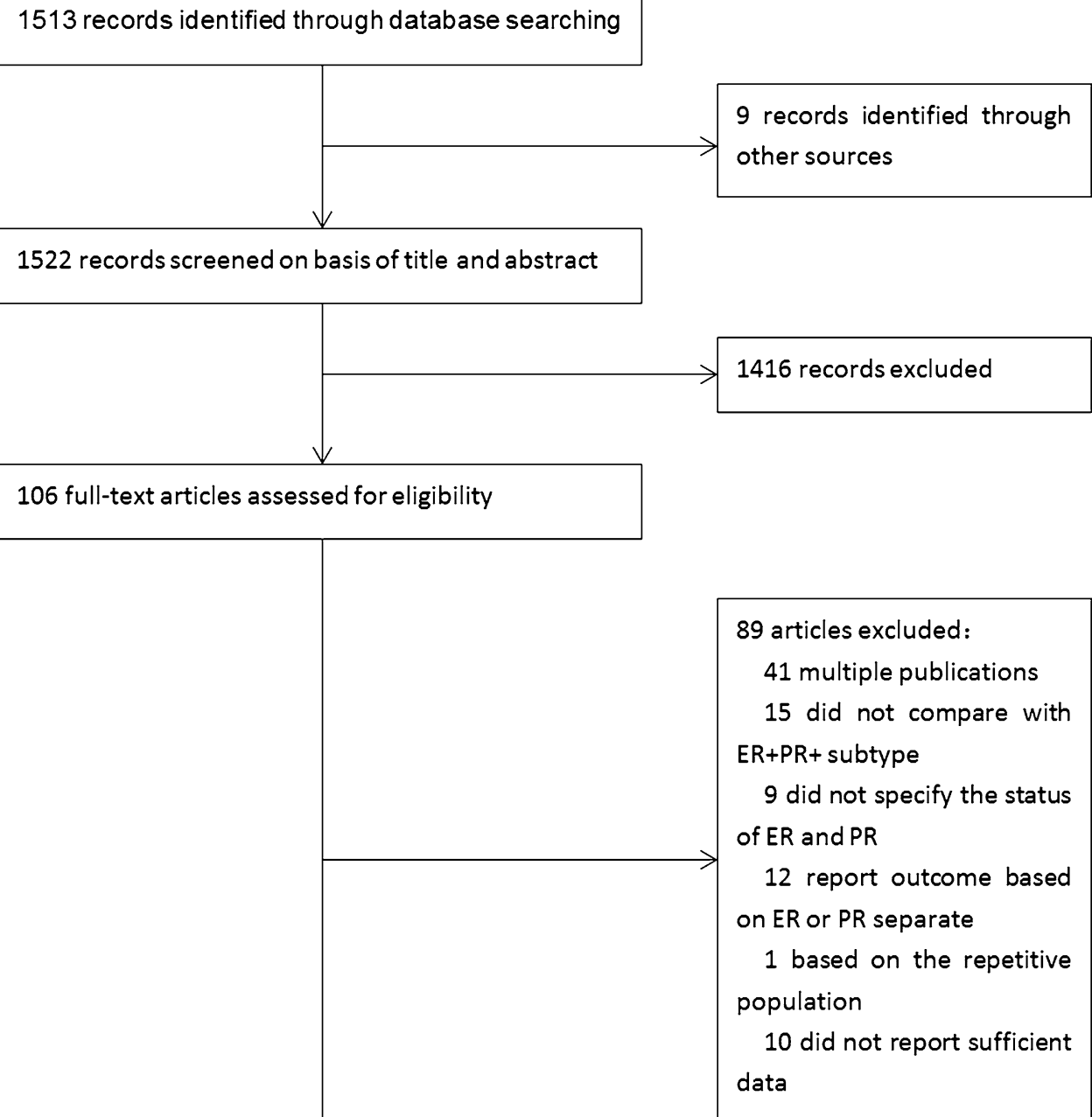

18 articles selected for final inclusion in meta-analysis
All analyses were conducted with Stata software (version 12.0), with $p$ values less than 0.05 considered significant.

\section{Results}

The systematic search finally identified 22 original studies, including 217,485 patients that met the inclusion criteria. All included studies were retrospective and cohort observational studies.

Table 1 provides a detailed summary of the baseline characteristics. Sixteen studies compared the prognosis of patients with ER+PR - tumours versus ER+PR+ tumours, of which 12 studies reported OS, 11 reported DFS and 4 reported BCSS. Twelve studies compared the prognosis of patients with $\mathrm{ER}-\mathrm{PR}+$ tumours versus $\mathrm{ER}+\mathrm{PR}+$ tumours. Among these studies, five reported OS, seven reported DFS and four reported BCSS. Most articles were published after
2003, except for the one that was published in 1996. Thirteen studies had a sample size of more than 500 patients. Two studies recognized $\geq 10 \%$ of tumour cells with nuclear staining as the cutoff for ER/PR positivity. Most studies used a cutoff of $\geq 1 \%$ to define ER/PR positivity. Two studies did not provide clear criteria for ER/PR positivity. Most patients received treatment according to the local standards.

\section{$\mathrm{ER}+/ \mathrm{PR}$ - tumours versus $\mathrm{ER}+/ \mathrm{PR}+$ tumours}

Eleven studies compared the prognosis of patients with ER+PR - tumours versus patients with ER+PR+ tumours using DFS. The meta-analysis showed a significantly increased risk of recurrence in patients with $\mathrm{ER}+\mathrm{PR}-$ tumours than in patients with $\mathrm{ER}+\mathrm{PR}+$ tumours $\left(I^{2}=0 \%\right.$, meta-analytic HR 1.60, 95\% CI 1.44-77) (Fig. 2a). There was no significant heterogeneity among the 11 studies $(p=0.718)$. When the analysis was limited to the nine 


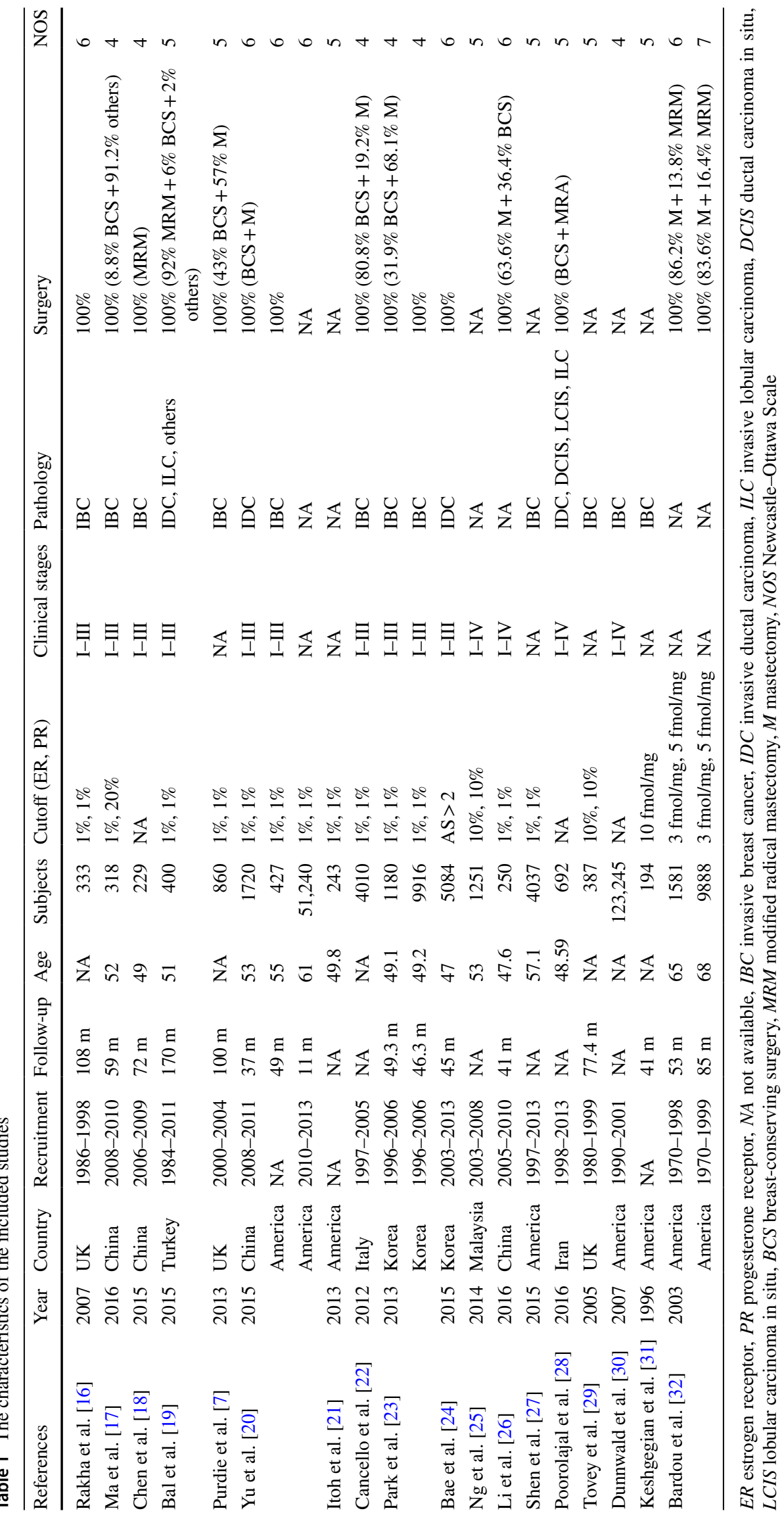


studies in which all patients received endocrine therapy, there was a significantly higher increased risk of recurrence in patients with $\mathrm{ER}+\mathrm{PR}-$ tumours than in patients with $\mathrm{ER}+\mathrm{PR}+$ tumours $\left(I^{2}=0 \%\right.$, meta-analytic HR 1.65 , 95\% CI 1.45-89) (Fig. 2b). The subgroup analysis based on HER2-negative status is shown in Fig. 2c. The pooled HR from the combined analysis was 1.57 (95\% CI, 1.32-1.87), which suggests that patients with $\mathrm{ER}+\mathrm{PR}-$ tumours have an increased risk of recurrence compared with that of patients with ER+PR+ tumours. In the lymph node-negative subgroup analysis, there was significantly more recurrence in patients with $\mathrm{ER}+\mathrm{PR}$ - tumours than in those with $\mathrm{ER}+\mathrm{PR}+$ tumours $\left(I^{2}=0 \%\right.$, meta-analytic HR $2.03,95 \%$ CI 1.44-86) (Fig. 2d).

OS was reported in ten studies. We pooled the data from those studies and found that $\mathrm{ER}+\mathrm{PR}+$ tumours were associated with a significantly better $\mathrm{OS}\left(I^{2}=30.6 \%\right.$, meta-analytic HR 1.38, 95\% CI 1.28-1.47) (Fig. 3a).

The association between ER+PR- tumours versus $\mathrm{ER}+\mathrm{PR}+$ tumours and death from $\mathrm{BC}$ was reported in four studies. The patients with ER+PR- tumours were $43 \%$ more likely to die from $\mathrm{BC}$ than those with $\mathrm{ER}+\mathrm{PR}+$ tumours (95\% CI 1.33-1.53) (Fig. 3b).

The funnel plots indicated the existence of a publication bias. The trim and fill showed that four of the studies did not change the results significantly. This suggests that systematic bias did not significantly contribute to our results (Supplementary Figure 1A, 1B, 1C).

\section{$E R-/ P R+$ tumours versus $E R+/ P R+$ tumours}

Six studies explored the outcome discrepancies in DFS between patients with ER-PR+ tumours and those with $\mathrm{ER}+\mathrm{PR}+$ tumours. The pooled effect was statistically significant, with the pooled HR being 2.27 (95\% CI 1.67-3.09) (Fig. 4a). This indicated that patients with ER-PR+ tumours have an increased risk of recurrence compared to patients with ER+PR+ tumours $\left(I^{2}=18.8 \%\right.$, meta-analytic HR 2.27, 95\% CI 1.67-3.09) (Fig. 4a). Subgroup analyses focusing on patients receiving ET found no difference in outcome between patients with the two types of tumours (HR 1.31, 95\% CI 0.71-2.42) (Fig. 4b). Subgroup analysis for patients with HER2-negative tumours showed that the HR was significantly increased in ER-PR+ tumours compared to ER+PR+ tumours (HR 3.10, 95\% CI 1.92-5.10) (Fig. 4c).

The pooled hazard ratio was 1.48 (95\% CI 1.17-1.89) (Fig. 5a), indicating that ER-PR+ tumours were associated with a worse $\mathrm{OS}$ than $\mathrm{ER}+\mathrm{PR}+$ tumours.

We also found that the risk of death from $\mathrm{BC}$ was significantly elevated in patients with ER-PR+ tumours compared to ER+PR+ tumours (HR 1.82, 95\% CI 1.68-1.98) (Fig. 5b).

No indication of publication bias was found based on the funnel plots (Supplementary Figure 2A, 2B, 2C).

\section{Discussion}

This meta-analysis demonstrates that patients with $\mathrm{ER}+\mathrm{PR}-$ and ER-PR+ tumours may have outcomes that are unsatisfactory compared to those of breast cancer patients with ER+PR+ tumours who receive ET.

We observed that patients with ER+PR+ tumours had significantly less recurrence and significantly superior survival compared to patients with $\mathrm{ER}+\mathrm{PR}$ - tumours. Similar results were obtained for all subgroups within these groups. Previous studies have reported that ER+PR- tumours are more likely to have higher levels of HER2 than those with $\mathrm{ER}+\mathrm{PR}+$ tumours, and the absence of PR may be a surrogate marker of aberrant growth factor signalling, which could contribute to tamoxifen resistance [33, 34]. Unfortunately, only one study reported the HR between $\mathrm{ER}+\mathrm{PR}+$ HER 2 + tumours and ER+PR - HER2 + tumours, with an HR of 1.58. However, in the HER2- subgroup analysis, our data show that ER+PR - tumours have a similarly high risk, with an HR of 1.57. This indicates that patients with $\mathrm{ER}+\mathrm{PR}$ - tumours have a worse prognosis, even if they are HER2 negative, which also supports the hypothesis that $\mathrm{PR}$ expression is an independent prognostic factor in breast cancer.

Several researchers have reported that ER+PR - tumours respond poorly to endocrine treatment $[34,35]$. A slightly higher risk of recurrence was found in our results for $\mathrm{ER}+\mathrm{PR}$ - tumours than for $\mathrm{ER}+\mathrm{PR}+$ tumours in the subgroup in which all patients received ET. These results again indicate a worse outcome for patients with $\mathrm{ER}+\mathrm{PR}-$ tumours than for patients with ER+PR+ tumours. However, patients with this type of tumour can still benefit from endocrine therapy, and it is essential that patients with this type of tumour receive endocrine therapy. A meta-analysis of individual early breast cancer patient data containing 20 trials of adjuvant tamoxifen versus no adjuvant tamoxifen found that the reduction in recurrence at 15 years in $\mathrm{ER}+\mathrm{PR}$ - patients seemed higher than that in ER+PR+ patients [36]. That is, ET strongly delayed relapse and improved survival of $\mathrm{ER}+\mathrm{PR}-$ patients. In addition, $\mathrm{ER}+\mathrm{PR}-$ tumours are originally aggressive and have a higher background risk of recurrence without treatment. As has been seen in some research findings, aromatase inhibitors and fulvestrant have much better treatment effects than tamoxifen in $\mathrm{ER}+\mathrm{PR}-$ patients $[37,38]$. Perhaps more aggressive ET, such as ovarian function suppression or ablation, and additional adjuvant chemotherapy could be considered to improve the poor prognosis of $\mathrm{ER}+\mathrm{PR}$ - patients.

The earliest theory to explain the development of this subset of breast cancer patients was that nonfunctional ER failed to stimulate PR production and finally led to the absence of estrogen, generating ER+PR- breast cancer [39, 40]. 
Fig. 2 a Meta-analysis results for DFS in $\mathrm{ER}+/ \mathrm{PR}$ - tumours compared with ER+/PR+ tumours. b All patients received endocrine therapy subgroup analysis results for DFS in $\mathrm{ER}+/ \mathrm{PR}$ - tumours compared with $\mathrm{ER}+/ \mathrm{PR}+$ tumours. c HER2-negative subgroup analysis results for DFS in $\mathrm{ER}+/ \mathrm{PR}-$ tumours compared with ER+/PR+ tumours. d Lymph node-negative subgroup analysis results for DFS in ER+/PR - tumours compared with $\mathrm{ER}+/ \mathrm{PR}+$ tumours
A Study ID $\%$ Rakha EA (2007) Ma RM (2016) Chen $\mathrm{H}(2015)$ Bal O (2015) Purdie CA (2013) Cancello $G$ (2012) Park S (2013) Bae SY 1 (2015) Bae SY 2 (2015) Li H 1 (2016) Li H 2 (2016) Shen T (2015) Tovey S (2005) Bardou VJ (2003)

Overall (I-squared $=0.0 \%, p=0.718$ )



$\mathrm{HR}(95 \% \mathrm{Cl}) \quad$ Weight

$1.37(1.12,1.80) \quad 18.25$ $2.17(1.12,4.18) \quad 2.38$ $2.16(1.07,4.35) \quad 2.10$ $2.02(1.24,3.27) \quad 4.37$ $1.72(1.17,2.52) \quad 7.01$ $1.41(1.15,1.73) \quad 24.64$ $1.66(1.13,2.44) \quad 6.88$ $1.58(0.74,3.38) \quad 1.77$ $2.12(1.20,3.76) \quad 3.16$ $2.50(1.00,6.30) \quad 1.22$ $0.58(0.10,3.44) \quad 0.32$ $1.75(1.37 .2 .78) \quad 8.20$ $2.08(1.09,3.85) \quad 2.58$ $1.61(1.25,2.04) \quad 17.12$ $1.60(1.44,1.77) \quad 100.00$
$\%$

B Study

ID HR $(95 \% \mathrm{Cl}) \quad$ Weight

Rakha EA (2007)

Ma RM (2016)

Chen H (2015)

Bal O (2015)

Park S (2013)

Li H 1 (2016)

Shen T (2015)

Tovey $S$ (2005)

Bardou VJ (2003)

Overall (l-squared $=0.0 \%, p=0.637$ )

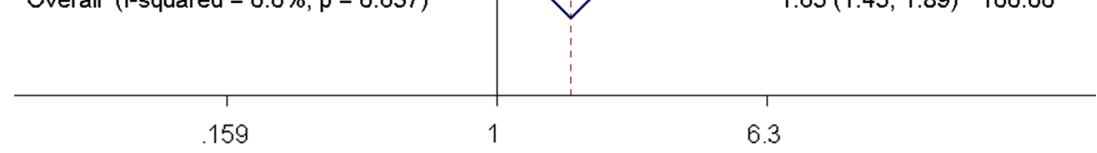

C Study

ID

Bal O (2015)

Cancello G (2012)

Bae SY (2015)

Li H 1 (2016)

Overall $(I-$ squared $=27.5 \%, p=0.247)$
$\mathrm{HR}(95 \% \mathrm{Cl})$

$\%$

$1.37(1.12,1.80) \quad 31.16$

$2.17(1.12,4.18) \quad 4.06$

$2.16(1.07,4.35) \quad 3.58$

$2.02(1.24,3.27) \quad 7.46$

$1.66(1.13,2.44) \quad 11.75$

$2.50(1.00,6.30) 2.08$

$2.00(1.39,4.00) \quad 6.28$

$2.08(1.09,3.85) \quad 4.40$

$1.61(1.25,2.04) \quad 29.24$

$2.02(1.24,3.27) \quad 13.09$

$1.41(1.15,1.73) \quad 73.80$

$2.12(1.20,3.76) \quad 9.47$

$72.50(1.00,6.30) \quad 3.64$

$1.57(1.32,1.87) \quad 100.00$ 
Fig. 2 (continued)

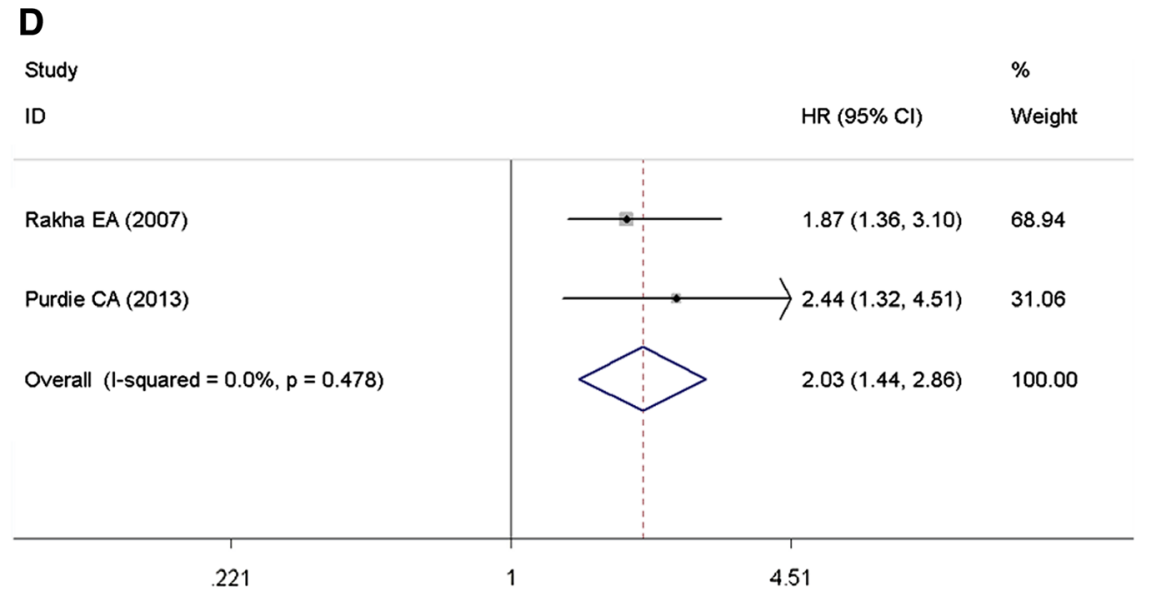

Actually, more than one mechanism can result in this phenotype and the reduced response to ET. Experimental data have implied that growth factor signalling mediates PR downregulation through the activation of the PI3K-Akt-mammalian target of rapamycin (mTOR) pathway [35]. Additionally, growth factors potentiate non-classical ER signalling, such as membrane-initiated steroid signalling (MISS) or other non-classical molecular pathways of signalling [41]. Molecular cross talk occurs between membranous ER and the growth factor signalling pathway; at the same time, the PR protein levels are down-regulated [42]. All of these molecular mechanisms promote tumour progression and lead to resistance to tamoxifen. However, these pathways do not completely account for the earlier recurrence and the relative unresponsiveness to ET of ER+PR - tumours, and additional mechanisms remain to be discovered.

As our data show, this phenomenon becomes more significant in the lymph node-negative subgroup, with a pooled hazard ratio (HR) of 2.03. Only one study reported DFS for a lymph node-positive subgroup, with a hazard ratio (HR) of 1.841. A possible explanation is that lymph nodepositive patients likely received more active management, such as radiotherapy and adjuvant chemotherapy. These results again demonstrate the higher risk of recurrence in $\mathrm{ER}+\mathrm{PR}$ - tumours without treatment. These results also indicate that even in lymph node-negative breast cancer, which is believed to be less invasive, $\mathrm{ER}+\mathrm{PR}-$ patients need more treatment than $\mathrm{ER}+\mathrm{PR}+$ patients.

In regard to $\mathrm{ER}-\mathrm{PR}+$ tumours, it remains unclear whether these tumours represent an established subtype. Some researchers have suggested that the ER-PR+ phenotype is a reproducible biologic subtype, but others have argued that it may represent a technical artefact [27, 43, 44]. A recent study reported that in a series of repeated immunohistochemistry analyses, using a new cutoff, the phenotype of only $36.7 \%$ of previously diagnosed ER-PR+ tumours remained stable [45]. Significantly, almost all studies have shown that ER-PR + tumours are biologically distinct from
$\mathrm{ER}+\mathrm{PR}$ - tumours and have a poor clinical outcome [46, 47]. Consistent with previous findings, our data also show that ER-PR + tumours are associated with a higher risk of recurrence and shorter survival than ER+PR+ tumours. Especially for DFS, the risk is increased by more than two times for the ER-PR+ group compared to the ER+PR+ group. No significant difference was seen in DFS between the subgroups of the endocrine treated patients, but we think this result is due to the small sample size.

The HER2 - subgroup displayed a higher risk differential between patients with ER-PR+ tumours and ER+PR+ tumours. The risk of recurrence increased the most with ER-PR + HER2 - tumours compared with ER+PR+ tumours, indicating that ER-PR+HER2- tumours behaved aggressively and that these patients have the worst clinical outcome of the hormone receptor-positive BC patients. $\mathrm{Yu}$ et al. suggested that the group of ER-PR + HER2- molecular subtype breast cancer patients consists of a majority of basallike tumours and a minority of luminal-like tumours [20]. Hefti found a trend towards low levels of PR in ER- breast cancer tumours [48]. An increasing body of evidence has shown that patients with ER-PR+ tumours share similar survival outcomes with ER-PR- BC patients. In addition, $\mathrm{ER}-\mathrm{PR}+$ tumour patients usually receive more adjuvant chemotherapy, which probably leads to an underestimation of the hazard ratio between ER-PR+ tumours and ER+PR+ tumours. Using current immunohistochemical technology, some patients will continue to be diagnosed with ER-PR+ tumours, although the number is low. It is important to recognize the high invasiveness and worse prognosis associated with ER-PR+ tumours compared to double hormone receptor-positive tumours.

A patient-level meta-analysis of randomized trials reported no apparent effect on recurrence at 5 years with tamoxifen treatment versus no adjuvant tamoxifen treatment in ER-low PR-positive disease [36]. This suggests that ER-PR+ tumours do not respond to endocrine therapy. Hammond et al. recommended repeated testing using 
Fig. 3 a Meta-analysis results for OS in ER+/PR - tumours compared with $\mathrm{ER}+/ \mathrm{PR}+$ tumours. b Meta-analysis results for BCSS in ER+/PR- tumours compared with $\mathrm{ER}+/ \mathrm{PR}+$ tumours
A

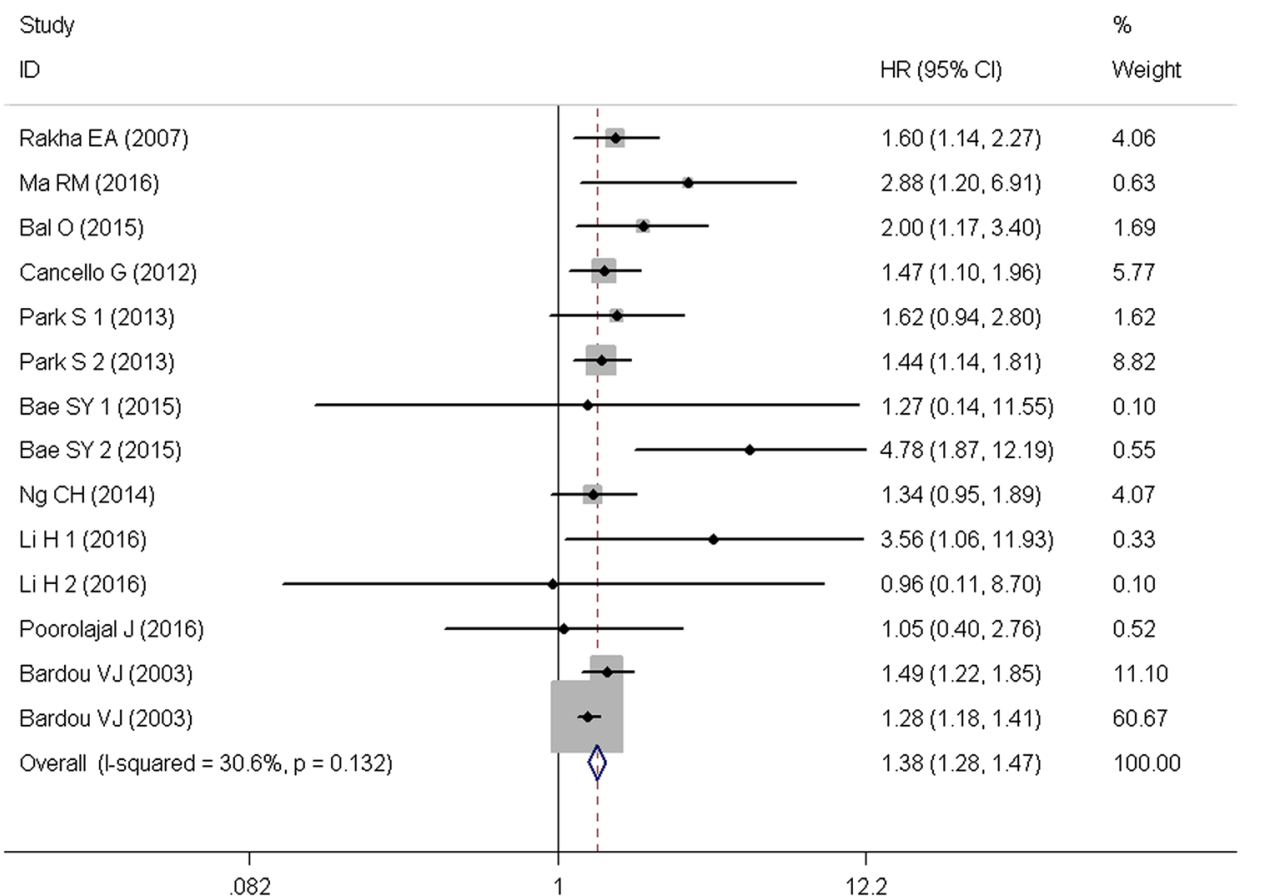

B

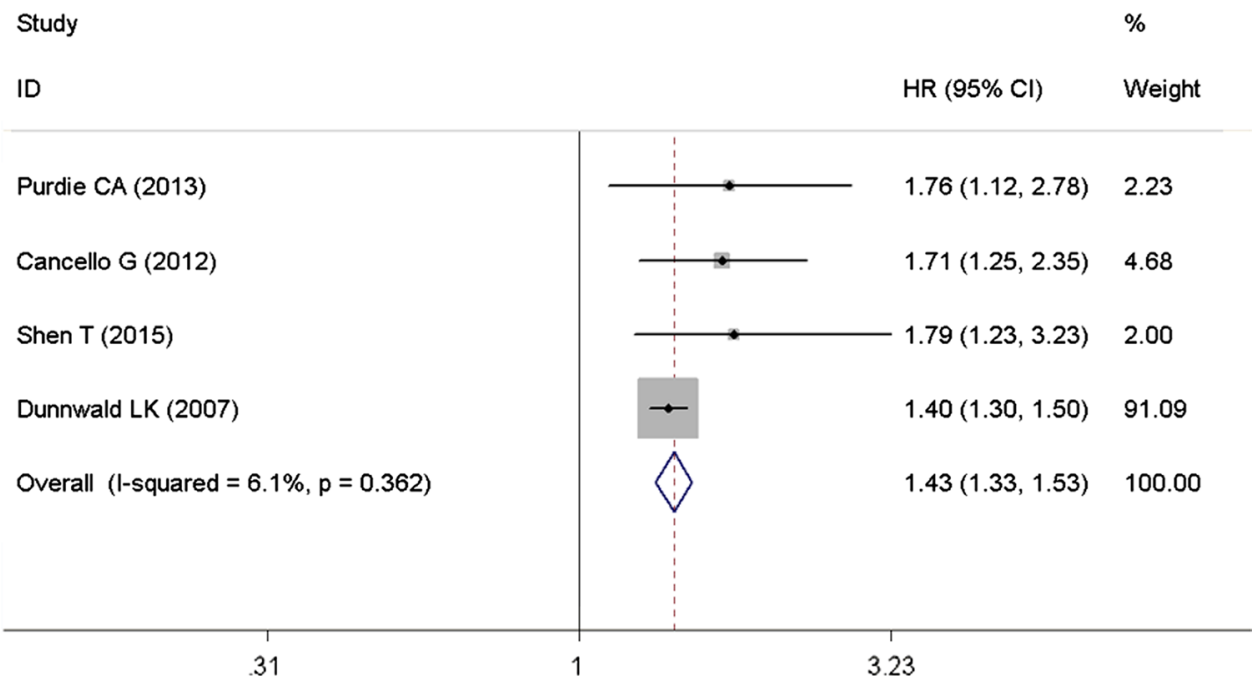

another tissue sample to eliminate false-negative ER assay results in patients who are likely to benefit from endocrine treatment [49]. Nevertheless, this benefit may be negligible. Hence, optional targeted therapeutic intervention for this type of tumour should be encouraged to achieve improved clinical outcome.

Moreover, three studies that were included in our analysis compared the outcome of patients with ER+PR - tumours and ER-PR+ tumours. Unfortunately, none of these studies found a significant difference in DFS between the two phenotypes, probably due to the small number of ER-PR+ tumours and the short follow-up period. Therefore, we did
Fig. 4 a Meta-analysis results for DFS in ER-/PR+ tumours compared with $\mathrm{ER}+/ \mathrm{PR}+$ tumours. b All patients received endocrine therapy subgroup analysis results for DFS in ER-/PR+ tumours compared with ER+/PR+ tumours. c HER2-negative subgroup analysis results for DFS in ER-/PR+ tumours compared with ER+/PR+ tumours

not combine the available data from those studies. However, patients with ER-PR+ tumours have a higher risk of recurrence events than $\mathrm{ER}+\mathrm{PR}$ - tumour patients when both groups are compared with $\mathrm{ER}+\mathrm{PR}+$ tumour patients. From this result, we can infer that the survival of patients with 


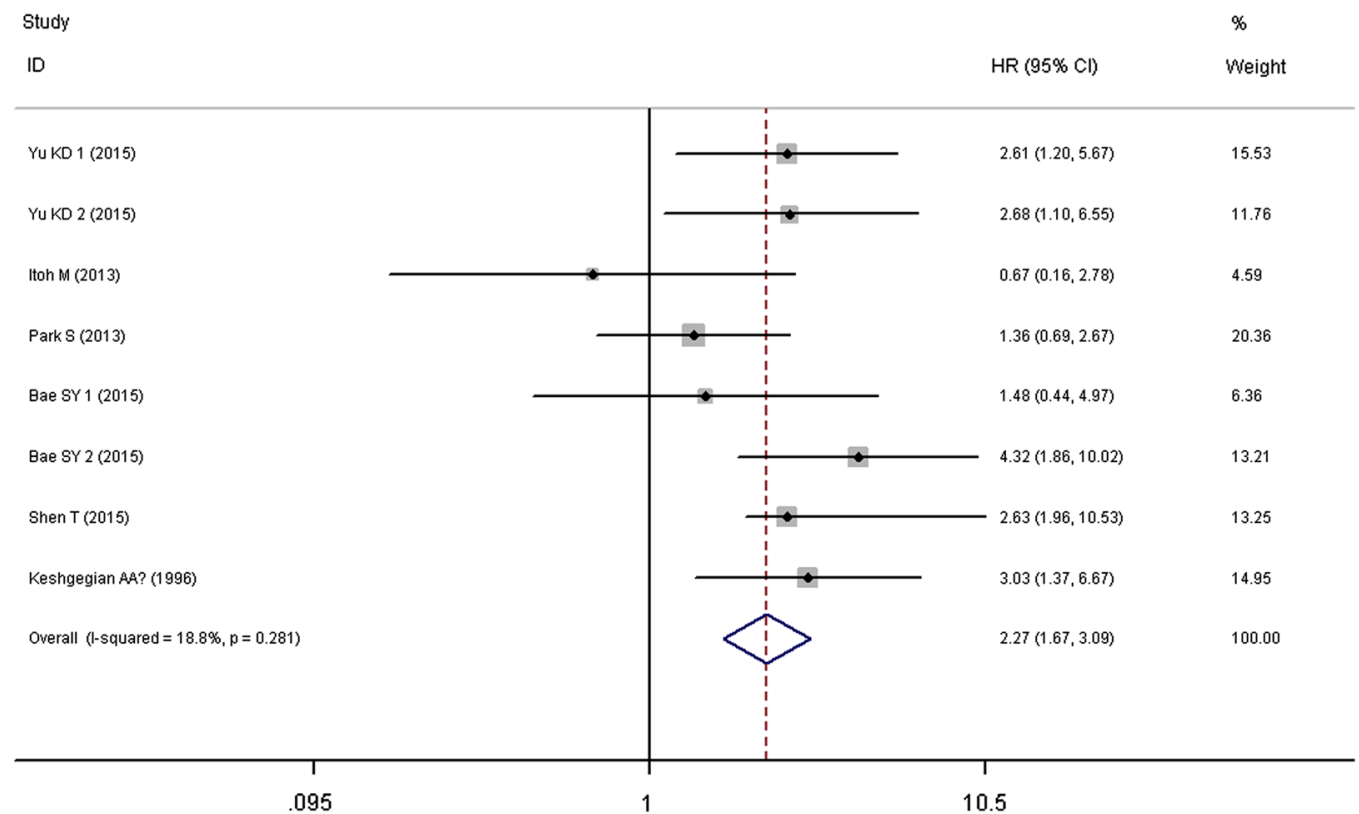

B Study

$\%$

ID

$\mathrm{HR}(95 \% \mathrm{Cl}) \quad$ Weight

Park S (2013)

Shen T (2015)

Overall (I-squared $=0.0 \%, p=0.799$ )

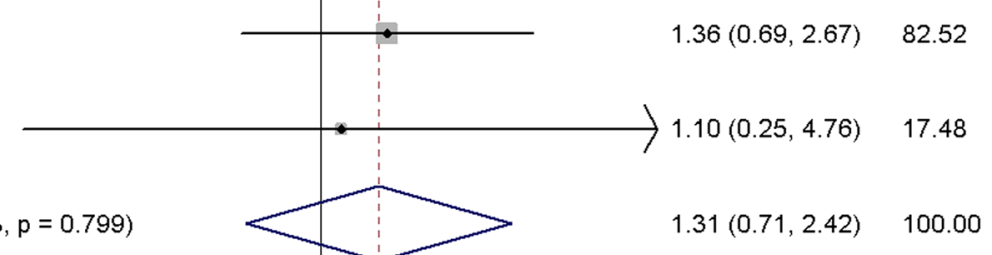

C Study $\%$

ID

$\mathrm{HR}(95 \% \mathrm{Cl}) \quad$ Weight

Yu KD 1 (2015)

Yu KD 2 (2015)

Bae SY 2 (2015)

Overall (I-squared $=0.0 \%, p=0.642)$

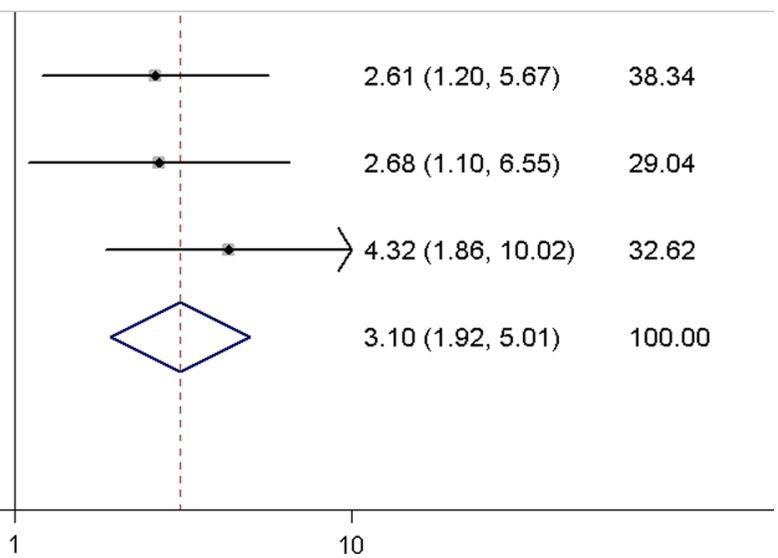




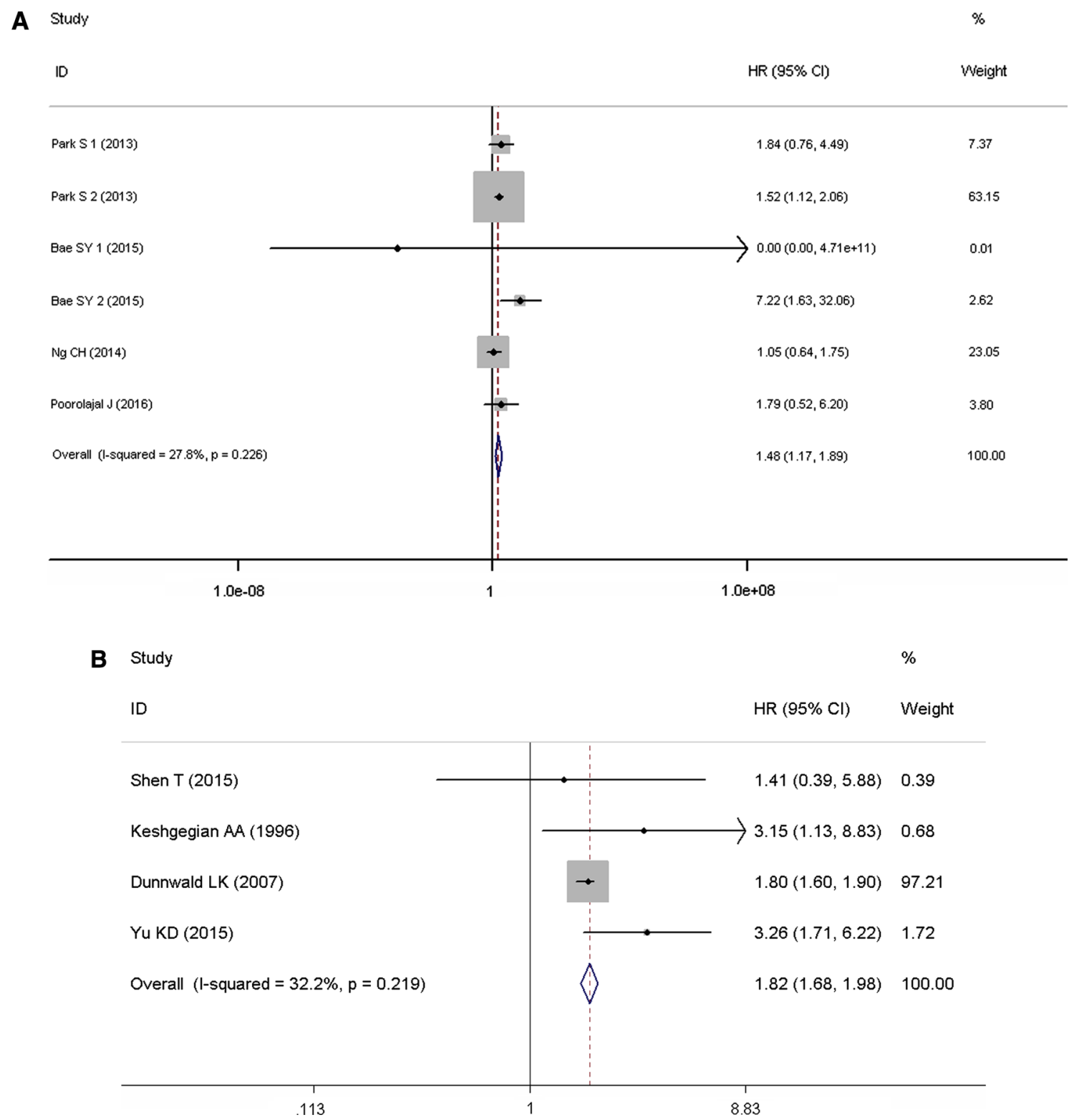

Fig. 5 a Meta-analysis results for OS in ER-/PR+ tumours compared with ER+/PR+ tumours. b Meta-analysis results for BCSS in ER-/PR+ tumours compared with $\mathrm{ER}+/ \mathrm{PR}+$ tumours

ER-PR+ tumours will be worse than that of patients with $\mathrm{ER}+\mathrm{PR}-$ tumours.

Our review and meta-analysis have several limitations. Despite a comprehensive literature search, the possibility of missing relevant studies cannot be ignored. Although we attempted to conduct a comprehensive systematic review and meta-analysis on this topic, the sample size of patients with ER-PR+ tumours was still small. A few studies used different levels of ER and PR expression for statistical analysis. Moreover, the difference between ER+PR - tumours and $\mathrm{ER}-\mathrm{PR}+$ tumours versus $\mathrm{ER}+\mathrm{PR}+$ has not been extensively studied in different clinical situations, such as HER2 positivity, LN positivity, with or without chemotherapy, and menopausal state. However, none of the studies that we reviewed provided any evidence to support the hypothesis that the risk of recurrence of $\mathrm{ER}+\mathrm{PR}-$ tumours or of $\mathrm{ER}-\mathrm{PR}+$ tumours was lower than that of $\mathrm{ER}+\mathrm{PR}+$ tumours, although some outcomes did not show a statistically significant difference. Another limitation is the possibility of publication bias in the literature, and most of the studies we reviewed were not prospective studies. Thus, we should interpret the results reported here with caution.

We conclude that in hormone receptor-positive breast cancer, even lymph node- and HER2-negative tumours, $\mathrm{ER}+\mathrm{PR}-$ tumours and $\mathrm{ER}-\mathrm{PR}+$ tumours are associated with a poor prognosis even with ET. The loss of either ER 
or PR helps to identify high-risk hormone receptor-positive $\mathrm{BC}$ patients. These two types of tumours require a more aggressive therapeutic strategy. To improve the survival of patients with these two types of tumours, further investigations focusing on the most appropriate endocrine therapy strategy or the development of targeted agents that can benefit these patients warrant investigation.

Author contributions FF, NW, YL and CW conceived and wrote the protocol of the study. NW, YL and PY performed the search, assessed the references for inclusion and extracted data from the studies. LC performed the statistical calculation. NW produced the manuscript, which was critically revised by FF and YL.

Funding sources/sponsors This work was supported by the National Nature Science Foundation (Grant number 81302320), National Key Clinical Specialty Construction Program (Grant number 201030404\#), Sci-Tech Key Program of Fujian Province (2013Y0040 and 2016J01549) and Medical Elite Cultivation Program of Fujian, P.R.C. (2013-ZQN-ZD-12).

\section{Compliance with ethical standards}

Conflict of interest The authors have declared no conflicts of interest.

Ethical approval This article does not contain any studies with human participants or animals performed by any of the authors.

Informed consent Informed consent was obtained from all individual participants included in the study.

Open Access This article is distributed under the terms of the Creative Commons Attribution 4.0 International License (http://creativeco mmons.org/licenses/by/4.0/), which permits unrestricted use, distribution, and reproduction in any medium, provided you give appropriate credit to the original author(s) and the source, provide a link to the Creative Commons license, and indicate if changes were made.

\section{References}

1. Beatson GT. On the treatment of inoperable cases of carcinoma of the manna; suggestion for a new method of treatment with illustrative cases. Lancet (London, England). 1896;2:104-7.

2. Adjuvant tamoxifen in the management of operable breast cancer: the Scottish Trial. Report from the Breast Cancer Trials Committee, Scottish Cancer Trials Office (MRC), Edinburgh. Lancet (London, England). 1987;2:171-5.

3. Early Breast Cancer Trialists' Collaborative Group. Tamoxifen for early breast cancer: an overview of the randomised trials. Lancet (London, England). 1998;351:1451-67.

4. Early Breast Cancer Trialists' Collaborative Group. Systemic treatment of early breast cancer by hormonal, cytotoxic, or immune therapy. 133 randomised trials involving 31,000 recurrences and 24,000 deaths among 75,000 women. Lancet (London, England). 1992;339:71-85.

5. Pichon MF, Pallud C, Brunet M, Milgrom E. Relationship of presence of progesterone receptors to prognosis in early breast cancer. Can Res. 1980;40:3357-60.
6. Olivotto IA, Truong PT, Speers CH, Bernstein V, Allan SJ, Kelly SJ, Lesperance ML. Time to stop progesterone receptor testing in breast cancer management. J Clin Oncol Off J Am Soc Clin Oncol. 2004;22:1769-70.

7. Purdie CA, Quinlan P, Jordan LB, Ashfield A, Ogston S, Dewar JA, Thompson AM. Progesterone receptor expression is an independent prognostic variable in early breast cancer: a populationbased study. Br J Cancer. 2014;110:565-72.

8. Fisher B, Anderson S, Tan-Chiu E, Wolmark N, Wickerham DL, Fisher ER, Dimitrov NV, Atkins JN, Abramson N, Merajver S, Romond EH, Kardinal CG, Shibata HR, Margolese RG, Farrar WB. Tamoxifen and chemotherapy for axillary node-negative, estrogen receptor-negative breast cancer: findings from National Surgical Adjuvant Breast and Bowel Project B-23. J Clin Oncol Off J Am Soc Clin Oncol. 2001;19:931-42.

9. Parmar MK, Torri V, Stewart L. Extracting summary statistics to perform meta-analyses of the published literature for survival endpoints. Stat Med. 1998;17:2815-34.

10. Tierney JF, Stewart LA, Ghersi D, Burdett S, Sydes MR. Practical methods for incorporating summary time-to-event data into metaanalysis. Trials. 2007;8:16.

11. Higgins JP, Thompson SG. Quantifying heterogeneity in a metaanalysis. Stat Med. 2002;21:1539-58.

12. Higgins JP, Thompson SG, Deeks JJ, Altman DG. Measuring inconsistency in meta-analyses. BMJ (Clinical research ed.). 2003;327:557-60.

13. Begg CB, Mazumdar M. Operating characteristics of a rank correlation test for publication bias. Biometrics. 1994;50:1088-101.

14. Duval S, Tweedie R. Trim and fill: a simple funnel-plot-based method of testing and adjusting for publication bias in meta-analysis. Biometrics. 2000;56:455-63.

15. Stang A. Critical evaluation of the Newcastle-Ottawa Scale for the assessment of the quality of nonrandomized studies in metaanalyses. Eur J Epidemiol. 2010;25:603-5.

16. Rakha EA, El-Sayed ME, Green AR, Paish EC, Powe DG, Gee J, Nicholson RI, Lee AH, Robertson JF, Ellis IO. Biologic and clinical characteristics of breast cancer with single hormone receptor positive phenotype. J Clin Oncol Off J Am Soc Clin Oncol. 2007;25:4772-8.

17. Ma RM, Chen CZ, Lin CQ, Zhan W, Guo GL. Lack of progesterone receptor expression predicts poor prognosis in patients with operable ER-positive invasive breast cancer. Chin J Oncol. 2016;38:687-92.

18. Chen H, Mo L, Xu XF, Gu J. Analysis of prognosis-related factors for breast cancer with positive estrogen receptors. Chin Clin Oncol. 2015;20:333-7.

19. Bal O, Yalcintas Arslan U, Durnali A, Uyetrk U, Demirci A, Tastekin D, Ekinci A, Esbah O, Turker I, Uysal Sonmez O, Oksuzoglu B. Progesterone receptor status in determining the prognosis of estrogen receptor positive/HER2 negative breast carcinoma patients. J BUON Off J Balkan Union Oncol. 2015;20:28-34.

20. Yu KD, Jiang YZ, Hao S, Shao ZM. Molecular essence and endocrine responsiveness of estrogen receptor-negative, progesterone receptor-positive, and HER2-negative breast cancer. BMC Med. 2015;13:254.

21. Itoh M, Iwamoto T, Matsuoka J, Nogami T, Motoki T, Shien T, Taira N, Niikura N, Hayashi N, Ohtani S, Higaki K, Fujiwara T, Doihara H, Symmans WF, Pusztai L. Estrogen receptor (ER) mRNA expression and molecular subtype distribution in ERnegative/progesterone receptor-positive breast cancers. Breast Cancer Res Treat. 2014;143:403-9.

22. Cancello G, Maisonneuve P, Rotmensz N, Viale G, Mastropasqua MG, Pruneri G, Montagna E, Iorfida M, Mazza M, Balduzzi A, Veronesi P, Luini A, Intra M, Goldhirsch A, Colleoni M. Progesterone receptor loss identifies luminal B breast cancer 
subgroups at higher risk of relapse. Ann Oncol Off J Eur Soc Med Oncol. 2013;24:661-8.

23. Park S, Park BW, Kim TH, Jeon CW, Kang HS, Choi JE, Hwang KT, Kim IC. Lack of either estrogen or progesterone receptor expression is associated with poor survival outcome among luminal A breast cancer subtype. Ann Surg Oncol. 2013;20:1505-13

24. Bae SY, Kim S, Lee JH, Lee HC, Lee SK, Kil WH, Kim SW, Lee JE, Nam SJ. Poor prognosis of single hormone receptorpositive breast cancer: similar outcome as triple-negative breast cancer. BMC Cancer. 2015;15:138.

25. Ng CH, Pathy NB, Taib NA, Ho GF, Mun KS, Rhodes A, Looi $\mathrm{LM}$, Yip $\mathrm{CH}$. Do clinical features and survival of single hormone receptor positive breast cancers differ from double hormone receptor positive breast cancers? Asian Pac J Cancer Prev APJCP. 2014;15:7959-64.

26. Li H, Zhao M, Tao P, Li H, Liu F, Li JY. Prognostic value of progesterone receptor status in Chinese breast cancer patients treated with tamoxifen. Int J Clin Exp Med. 2016;9:2175-83.

27. Shen T, Brandwein-Gensler M, Hameed O, Siegal GP, Wei S. Characterization of estrogen receptor-negative/progesterone receptor-positive breast cancer. Hum Pathol. 2015;46:1776-844.

28. Poorolajal J, Nafissi N, Akbari ME, Mahjub H, Esmailnasab N, Babaee E. Breast cancer survival analysis based on immunohistochemistry subtypes (ER/PR/HER2): a retrospective cohort study. Arch Iran Med. 2016;19:680-6.

29. Tovey S, Dunne B, Witton CJ, Forsyth A, Cooke TG, Bartlett JM. Can molecular markers predict when to implement treatment with aromatase inhibitors in invasive breast cancer? Clin Cancer Res Off J Am Assoc Cancer Res. 2005;11:4835-42.

30. Dunnwald LK, Rossing MA, Li CI. Hormone receptor status, tumor characteristics, and prognosis: a prospective cohort of breast cancer patients. Breast Cancer Res BCR. 2007;9:R6.

31. Keshgegian AA, Cnaan A. Estrogen receptor-negative, progesterone receptor-positive breast carcinoma: poor clinical outcome. Arch Pathol Lab Med. 1996;120:970-3.

32. Bardou VJ, Arpino G, Elledge RM, Osborne CK, Clark GM. Progesterone receptor status significantly improves outcome prediction over estrogen receptor status alone for adjuvant endocrine therapy in two large breast cancer databases. J Clin Oncol Off J Am Soc Clin Oncol. 2003;21:1973-9.

33. Colditz GA, Rosner BA, Chen WY, Holmes MD, Hankinson SE. Risk factors for breast cancer according to estrogen and progesterone receptor status. J Natl Cancer Inst. 2004;96:218-28.

34. Arpino G, Weiss H, Lee AV, Schiff R, De Placido S, Osborne CK, Elledge RM. Estrogen receptor-positive, progesterone receptor-negative breast cancer: association with growth factor receptor expression and tamoxifen resistance. J Natl Cancer Inst. 2005;97:1254-61.

35. Cui X, Schiff R, Arpino G, Osborne CK, Lee AV. Biology of progesterone receptor loss in breast cancer and its implications for endocrine therapy. J Clin Oncol Off J Am Soc Clin Oncol. 2005;23:7721-35.

36. Davies C, Godwin J, Gray R, Clarke M, Cutter D, Darby S, McGale P, Pan HC, Taylor C, Wang YC, Dowsett M, Ingle J, Peto R. Relevance of breast cancer hormone receptors and other factors to the efficacy of adjuvant tamoxifen: patient-level meta-analysis of randomised trials. Lancet (London, England). 2011;378:771-84.

37. Zhang Y, Su H, Rahimi M, Tochihara R, Tang C. EGFRvIIIinduced estrogen-independence, tamoxifen-resistance phenotype correlates with $\mathrm{PgR}$ expression and modulation of apoptotic molecules in breast cancer. Int J Cancer. 2009;125:2021-8.

38. Punglia RS, Kuntz KM, Winer EP, Weeks JC, Burstein HJ. The impact of tumor progesterone receptor status on optimal adjuvant endocrine therapy for postmenopausal patients with early-stage breast cancer: a decision analysis. Cancer. 2006; 106:2576-82.

39. Horwitz KB, McGuire WL. Predicting response to endocrine therapy in human breast cancer: a hypothesis. Science (New York, N.Y.). 1975;189:726-7.

40. Horwitz KB, Koseki Y, McGuire WL. Estrogen control of progesterone receptor in human breast cancer: role of estradiol and antiestrogen. Endocrinology. 1978;103:1742-51.

41. Schiff R, Massarweh SA, Shou J, Bharwani L, Mohsin SK, Osborne CK. Cross-talk between estrogen receptor and growth factor pathways as a molecular target for overcoming endocrine resistance. Clin Cancer Res Off J Am Assoc Cancer Res. 2004;10:331s-6s.

42. Osborne CK, Shou J, Massarweh S, Schiff R. Crosstalk between estrogen receptor and growth factor receptor pathways as a cause for endocrine therapy resistance in breast cancer. Clin Cancer Res Off J Am Assoc Cancer Res. 2005;11:865s-70s.

43. De Maeyer L, Van Limbergen E, De Nys K, Moerman P, Pochet N, Hendrickx W, Wildiers H, Paridaens R, Smeets A, Christiaens MR, Vergote I, Leunen K, Amant F, Neven P. Does estrogen receptor negative/progesterone receptor positive breast carcinoma exist? J Clin Oncol Off J Am Soc Clin Oncol. 2008;26:335-6 (author reply 336-338).

44. Ahmed SS, Thike AA, Zhang K, Lim JC, Tan PH. Clinicopathological characteristics of oestrogen receptor negative, progesterone receptor positive breast cancers: re-evaluating subsets within this group. J Clin Pathol. 2017;70:320-6.

45. Creighton CJ, Kent Osborne C, van de Vijver MJ, Foekens JA, Klijn JG, Horlings HM, Nuyten D, Wang Y, Zhang Y, Chamness GC, Hilsenbeck SG, Lee AV, Schiff R. Molecular profiles of progesterone receptor loss in human breast tumors. Breast Cancer Res Treat. 2009;114:287-99.

46. Kiani J, Khan A, Khawar H, Shuaib F, Pervez S. Estrogen receptor alpha-negative and progesterone receptor-positive breast cancer: lab error or real entity? Pathol Oncol Res POR. 2006;12:223-7.

47. Yu KD, Di GH, Wu J, Lu JS, Shen KW, Liu GY, Shen ZZ, Shao ZM. Breast cancer patients with estrogen receptor-negative/progesterone receptor-positive tumors: being younger and getting less benefit from adjuvant tamoxifen treatment. J Cancer Res Clin Oncol. 2008;134:1347-54.

48. Hefti MM, Hu R, Knoblauch NW, Collins LC, Haibe-Kains B, Tamimi RM, Beck AH. Estrogen receptor negative/progesterone receptor positive breast cancer is not a reproducible subtype. Breast Cancer Res BCR. 2013;15:R68.

49. Hammond ME, Hayes DF, Wolff AC, Mangu PB, Temin S. American Society of Clinical Oncology/College of American Pathologists guideline recommendations for immunohistochemical testing of estrogen and progesterone receptors in breast cancer. J Oncol Pract. 2010;6:195-7.

Publisher's Note Springer Nature remains neutral with regard to jurisdictional claims in published maps and institutional affiliations. 